This article was downloaded by: [University of Waikato Library]

On: 18 November 2009

Access details: Access Details: [subscription number 907696412]

Publisher Routledge

Informa Ltd Registered in England and Wales Registered Number: 1072954 Registered office: Mortimer House, 3741 Mortimer Street, London W1T 3JH, UK

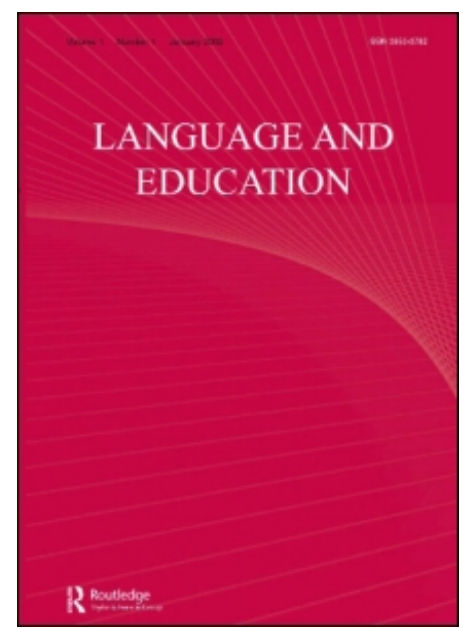

\title{
Language and Education
}

Publication details, including instructions for authors and subscription information:

http://www.informaworld.com/smpp/title content=t794297816

\section{Literacy Research Methodology That Is Up to the Challenge}

John Smyth ${ }^{\text {a }}$ David Whitehead ${ }^{\mathrm{b}}$

${ }^{a}$ School of Education, University of Ballarat, Australia ${ }^{\mathrm{b}}$ School of Education, University of Waikato,

Hamilton, New Zealand

To cite this Article Smyth, John and Whitehead, David'Literacy Research Methodology That Is Up to the Challenge', Language and Education, 21: 5, 377 - 386

To link to this Article: DOI: $10.2167 /$ le798.0

URL: http://dx.doi.org/10.2167/le798.0

\section{PLEASE SCROLL DOWN FOR ARTICLE}

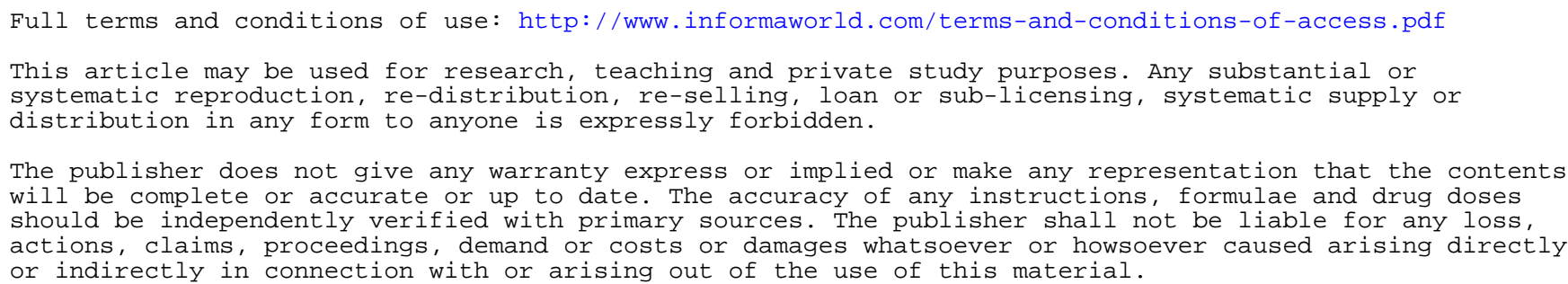




\title{
Literacy Research Methodology That Is Up to the Challenge
}

\author{
John Smyth \\ School of Education, University of Ballarat, Australia
}

\author{
David Whitehead \\ School of Education, University of Waikato, Hamilton, New Zealand
}

\begin{abstract}
This paper outlines the methodological dimensions of the secondary literacy research evaluation that is the focus of this special issue - the New Zealand-based Secondary Schools' Literacy Initiative (SSLI). We argue that these methodological dimensions are an example of the type of contextualised and critical research that might be usefully applied in exploring literacy across the curriculum in other national contexts. A particular concern addressed in the paper is the need to develop a contextualised, rich description of literacy practices in schools, while also addressing a wider policy climate, which is often preoccupied with issues of literacy achievement and, particularly, often-entrenched differential achievement for students across class and ethnicity lines. To achieve this, the researchers adopted a quasi-ethnographic, multi-locale, mixed-methods approach intended to enhance the robustness of the research design and the validity of the results.
\end{abstract}

doi: $10.2167 /$ le 798.0

Keywords: multi-faceted methodology, partial ethnography, ecological validity, interactive trouble, multi-locale ethnography, teacher-friendly assessment

\section{Introduction}

The Secondary Schools' Literacy Initiative (SSLI) was established under broad parameters aimed at lifting pedagogical practices across the education sectors in Aotearoa/New Zealand. The intervention was also the result of growing concern about student literacy achievement, particularly the so-called 'literacy tail', comprising a disproportionate number of disadvantaged and/or 'at risk' students, many from cultural and linguistic minority backgrounds. Following on from a successful programme for primary (elementary) schools in 2001, secondary schools in 2002 were invited to participate in literacy leadership workshops. This initial consciousness-raising about literacy among key secondary school staff formed the basis of the subsequent SSLI intervention in schools from 2003 to 2005 . Selected schools (60 over the course of the three-year SSLI intervention; 20 schools per year) received support from a regional literacy facilitator who provided leadership and professional development and, in return, schools planned, implemented and reviewed classroom goals and activities for literacy improvement. At the end of each year, the 20 schools involved for that year reported on literacy achievements. 
Almost all of the schools examined in the SSLI research were ones with a heterogeneous socioeconomic student mix that was slanted in the direction of a preponderance of lower percentile (disadvantaged) schools. This should not surprise us because schools that are struggling most with literacy issues are the ones in which there is often the greatest mismatch between the school's socio-economic student intake, and the middle class expectations that improved life chances are highly dependent on high literacy levels. What is less evident, and proving more than a little intractable, is what can be done about this.

A way of 'naming' this is in terms of 'interactive trouble' (Freebody et al., $1995)$ - that is to say, the dissonance or disconnect between students' lives, experiences and aspirations, and the expectations and rationale of the school and the wider education system regarding literacy performance outcomes. Given this reality, Thrupp and Lupton (2006) helpfully invoke Bell (2003) in arguing that it makes little sense to demonise, blame or punish those who are already suffering and struggling most with literacy constraints, and it makes more sense to work constructively and productively with them in directions that may provide some hope of possible resolution. In other words, if we want to bring about improvements in literacy among those most in need of improving, then we have to get up close to and understand local efforts in schools that are attempting to do this. Concomitantly, it is 'imperative to take schools' highly distinctive contexts seriously' (p. 308). With the kind of student clientele involved, this also means having a social justice agenda - pedagogically, organisationally, structurally and in terms of school culture. What research evidence is increasingly telling us is that student achievement, especially in respect of literacy and from within the quarters being spoken about here, is much more context-dependent than we have been led to believe up to this point. Understanding the constraints and the possibilities within 'contextualised practice' (Thrupp \& Lupton, 2006: 308), means that we have to confront, contest and refute research approaches that 'bleach context from their analytic frame' (Slee et al., 1998: 5).

All of this is by way of saying that understanding how schools go about improving literacy across the school for students who do not present with middle class cultural capital, requires methodological research approaches that have a capacity to get up close and understand how schools and teachers are developing and sustaining innovative, engaging and culturally relevant approaches to literacy. In our research, and this is not at all unusual these days, there were also requirements from the provider of research funding that the research measure quantitatively the impact of the SSLI on student literacy achievement. This imperative necessitated the administration of some psychometric measures across the research cohort for comparative purposes and to determine effect sizes.

The SSLI study thus sought to address the complexities that accompany a whole-school approach to literacy through a research methodology that employed case studies (some of which were longitudinal), that amounted in effect to 'multi-sited' quasi-ethnographies (Marcus, 1998) of 12 secondary schools (from the larger pool of 60 over 3 years). Alongside this, we used a process of tracking literacy achievement through assessment practices, undertaken from 2003 to 2006. 
Our research approach had a number of defining features:

- Situated: in that the primary focus of the research was upon the way in which teachers, school leaders and students experienced and made sense of attempts to provide them with different ways of envisaging and acting in respect of literacy. The personal and collective repertoires of literacy 'best practices', constructed as a consequence through teachers' theory-building approaches, are regarded as crucial artefacts of 'collaborative knowledge building' (Alton-Lee, 2005: 2).

- Sociocultural: in that it began from the perspective that the lived teaching and learning experiences of teachers and students are important, valuable and worthwhile, not only contextually, but in and of themselves.

- Constructionist: in that it endorsed the view that the inhabitants of schools are credible and 'authoritative informants' that have efficacious ways of making meaning about literacy, and that they possess valuable knowledge about relational, contextual, social and political interpretations of the circumstances of literacy teaching and learning.

- Multimodal: in that it acknowledged the view that understanding something as complex as literacy in secondary schools requires multiple ways of knowing, some of which are of a meaning-making type, but others, which are equally valuable, that involve surveying, measuring and calibrating what is occurring.

- Socially critical: in that a preponderance of the New Zealand secondary schools involved in the research were ones that were struggling the most with how to improve literacy for the most disadvantaged students. In this sense, there were major issues in the research around who the mainstream or general literacy curriculum works for, whose knowledge is privileged and how and in what ways literacy teaching might occur in ways that are inclusive of the most marginalised (see also May and Wright, this issue).

\section{Combining Qualitative and Quantitative Research}

The more specific methodological research approaches involved both qualitative and quantitative dimensions:

\section{Qualitative dimensions}

(1) This relied upon detailed conversations with teachers and students, along with classroom observations, and the collection of classroom artefacts of teaching strategies (when available). The 'conversations with a purpose' (Burgess, 1988) that occurred through our embedded classroom interview approach, enabled the construction of detailed case portraits of schools (Wright et al., 2004, 2005a, 2005b, 2006) that foregrounded both our more detailed analytical work, while at the same time informing schools and policymakers.

(2) Relied upon participant observation in which the research observer assisted teachers to enhance their knowledge of literacy strategies and assessment protocols through post-observation discussions.

(3) In this aspect, results obtained from a questionnaire sent out to all schools involved in the SSLI (Wright et al., 2005a) were used to indicate the 
effectiveness of the professional learning programme delivered to schools, and to also indicate the impact SSLI was having on students' literacy achievement, attitudes, school culture, departmental processes and programmes of work.

\section{Quantitative dimensions}

(1) The attempt here was to obtain an 'objective' measure of change through the administration of the Essential Skills Assessment: Finding information in Prose Text (NZCER, 2001) instrument to a sample of Years 9 and 10 students. This occurred in the case study schools at the beginning and end of the intervention period each year, and the results were shared with the New Zealand Ministry of Education (Whitehead et al., 2004) and the schools to foster further discussion about the SSLI.

(2) This element comprised the development of locally sensitive literacy tests for teachers that informed teachers' literacy practices in ways that were teacher-friendly and that translated into strategies that helped students to learn. To that extent, it is argued that what was occurring here were forms of literacy assessment that not only had credibility but that also possessed 'ecological validity' (see also Whitehead, this issue).

We believe that the methodological diversity and the overall 'ecological paradigm' (Alton-Lee et al., 2000: 187) out of which we were working through our research provide an approach that is highly consistent with the kind of relational and reflexive pedagogical complexity of the schools being studied, as well as a possible template for other research of this kind.

\section{Qualitative Research Methodologies}

Methodologically, the approach used in the qualitative case study aspect was in the style of illuminative portrayals of Parlett and Hamilton (1975). We were interested in taking account of the wider context within which the literacy initiative was occurring - how it operated, what was influencing what transpired in schools and what was contributing to or illuminating 'those elements in the education effort, which seemed to have had desirable results' (Parlett \& Hamilton, 1975: 89). In particular, we were interested in capturing something of the 'learning milieu' (p. 90) - the 'nexus of cultural, social, institutional and psychological variables' that 'interact in complicated ways to produce... a unique pattern of circumstances, pressures, customs, opinions and work styles which suffuse the teaching and learning that occurs there' (p. 90). In other words, we wanted to know about the 'diversity and complexity of learning milieux' (p. 90) when an innovative initiative of the kind implicit in the literacy initiative occurred, and the responses of teachers and students.

\section{Sample schools}

Of the 20 schools that elected to join the SSLI programme each year, four were selected each year by the research team for their suitability as research sites after a preliminary one-day visit to the school to ascertain the school's readiness to join the programme and to locate preliminary evidence of likely innovative literacy activities. During that visit the role of the research team was explained, 
an explanation provided of how the research would be carried out, an attempt made to gauge the readiness of the school to engage with literacy, a perusal made of the extent of the school's literacy plans and evidence sought as to what they had already achieved in respect of literacy improvements.

It was important that the schools selected for study were ones broadly representative of secondary schools in New Zealand. Over the three-year life of the research evaluation, schools were chosen that fitted within a broad group of criteria that ensured:

- regional, rural/urban spread

- single sex/co-educational

- socioeconomic range

- literacy leader in school (e.g. subject background, time allowance, status in school, length of service in school, male/female, types of actions to support/develop literacy)

- size and type of school (e.g. Years 7-13, 9-13; integrated/state; small/large)

- readiness and uptake of literacy within school

- ethnic composition

- new/well-established schools

\section{Interviews and classroom observations}

Research team visits of two days' duration involved in-depth interviews (recorded on a digital audio recorder) with the Senior Management Team (SMT) member responsible for the literacy initiative. The literacy leader was also interviewed, as were classroom teachers across subject areas. Interviews typically took between 30 minutes to an hour. Typical questions included:

- What is literacy?

- How is the school interpreting this?

- Why is literacy important?

- Whose problem is literacy?

- What is the school doing about literacy?

- How does the school know it is making a difference?

Interviews were digitally recorded, together with an in situ process of selective verbatim transcription undertaken by an experienced speed touch typist in the style of a Hansard reporter, using a laptop computer.

Classroom observations were undertaken to provide a context for the interview conversations with teachers, along with interviews of students and tours of the school. The researchers took digital photographs to assist in remembering the contexts and to assist in making sense of the data. Field notes of classroom observations and impressions of the school and its teaching and literacy practices were also made. Each school received a second shorter visit later in the year to examine progress made in relation to literacy objectives, plans for the following year and issues still to be addressed.

\section{Analysis of the data}

The interview data, classroom observations, photographs and documentary artefacts of teaching and learning, were used to construct detailed descriptive 
narrative portrayals of each school - 12 in total. During the writing of the case records for each school the transcripts together with the digital audio recordings and photographs were used for verification, elaboration and as a reminder of the context of the interview conversation. This use of multiple data sources enhanced the account and provided a means of cross-checking recorded interviews. These case records contained an orienting description of the physical spaces of the school and its geography, followed by a number of themes that emerged in relation to literacy. In the first year, 2003, the thematic pattern included: the role of the literacy leader; the function of the senior management team in literacy; activities of the regional literacy facilitator; extent of buy-in from staff; literacy strategies in classrooms; the status of English as a Second Language; the sustainability of a literacy focus in the school; key issues around literacy for the school, and how the school envisaged operating in the future.

In the second (2004) and third (2005) years, the case study format altered somewhat to present information in a way that reflected a more grounded approach in which the ideas were emerging from the data, including: students' voices; teachers' voices; principals' voices; resistance versus uptake; role of HODs/HOFs (Head of Departments/Head of Faculties); literacy leaders; regional facilitators; and conclusion.

There was also a longitudinal qualitative component to this research that focussed on how schools were sustaining cross-curricular literacy programmes. In 2005, the research team returned to four schools that were part of the SSLI - three of these schools had been case study schools, and the fourth one had not. The kind of indicative questions animating this aspect of the research included:

- What has happened since the school was in the SSLI cluster (including changes to key staff)?

- Which professional development models are successful?

- What changes to pedagogy, attitudes and teacher beliefs have taken place?

- What is the school's literacy capacity now?

- Has improvement to students' literacy outcomes been sustained?

- What changes have there been in the school's collection, analysis and use of literacy data?

- What particular language and literacy strategies have been most effective?

- What are the resourcing implications for schools (including external support, staffing, structural changes)?

- To what extent does the school have integrated language/literacy policies in place, and how do they affect what happens?

More detailed findings from this aspect are canvassed by May in this issue.

\section{Quantitative Research Methodologies}

The key quantitative measures used were (1) the Essential Skills Assessment: Finding Information From Prose Text (ESA) (NZCER, 2001), administered in March and October of 2004 and 2005, and (2) ecologically valid teacher-made assessments. 


\section{The Essential Skills Assessment: Finding information from prose text}

The bases that underpin research methods that employ 'central' psychometric measures of literacy achievement like the Essential Skills Assessment: Finding Information From Prose Text (ESA) (NZCER, 2001) have been the focus of sustained criticism for many years (Amrein \& Berliner, 2002; Ions, 1977). Criticism has focussed on the extent to which these measures construct mechanistic and reductionist views of literacy, which favour forms of literacy consistent with the cultural capital of the ruling class. These views of literacy favour the reading and writing of academic texts and exclude notions of literacy associated with, for example, text messages and multimodal digital texts. When, in the context of literacy assessment protocols, quantification of preferred slivers of literacy becomes an end in itself, or even an activity that serves the will of centralised institutions (Freebody \& Wyatt-Smith, 2004), it echoes Horkheimer's (1972) general criticism of positivism as 'the mathematication of nature', or in this case, of literacy.

In a best case scenario, the goal when selecting a psychometric measure of literacy is to demonstrate that it is fit for the purpose for which it was intended, and the context in which it is to be administered. The ESA, administered as a requirement of the SSLI research focussed on a sliver of information literacy, namely the ability to skim, scan and take notes (linked to the skill of comprehending text structure). This was assumed to be an aspect of the literacy construct that would be sensitive to the range of school-based interventions provided by the SSLI facilitators. When a single psychometric measure is used to assess changes in literacy achievement associated with professional learning interventions, the multimodal dimensions of the literacy construct, are, per force, neglected. As such, the use of the ESA reinforced particular constructions of literacy and re-enforced the construction of human behaviour and literacy achievement as 'rule-governed'. It constructed changes in literacy achievement associated with the SSLI as responses to external events that lay in the past and, in particular, to the work of facilitators and literacy leaders. In contrast, the qualitative research methodology outlined earlier was future-orientated - this methodology helped to describe the intentions of people concerned (or otherwise) with the literacy education of students.

Although there are, clearly, concerns about using psychometric measures of literacy achievement, the advantages of using (Cohen et al., 2000) normreferenced measures of literacy achievement lie in their power to compare student literacy achievement relative to other students, nationally. Additionally, they have the advantage of 'objectivity'; they have been trialled and refined, and standardised (thus providing information about the performance of students along gender, decile and ethnic dimensions). Psychometric measures of literacy achievement are also 'reliable' and 'valid' measures; they enable statistical analysis of results, and are often quick to administer. In this regard, the ESA test is three-monthly normed from March and designed for use with students in Years 7 and 8 (Intermediate school version) and Years 9 and 10 (Secondary school version). The test is in two sections: Section 1, completed in 10 minutes, probes students' ability to skim read. Section 2, completed in 20 minutes, probes students' ability to take notes and comprehend text structure. This is a more rigorous section of the test. The main purpose of the ESA, reflected in the rating 
scale, was formative assessment. However, comparative data for individual and group assessment were available in the form of stanines.

As part of the profile for improving literacy for all in secondary schools, two lines of psychometric assessment were adopted; a pre-test/post-test process using the ESA for students in schools involved on an annual basis, and second, a process for students in the first year of the study who then participated in the longitudinal evaluation over three years.

A sample of Year 9 and 10 students in each of the 20 schools involved in the SSLI programme in 2004 and 2005 were evaluated using a pre-test/post-test design. The aim of the sampling procedure was to make generalisations in respect to the population of Year 9 and 10 students. It was, therefore, important to evaluate a representative sample that comprised near-equal numbers based on gender, ethnicity and reading ability. In schools where Year 9 and 10 classes were streamed on [reading/English] ability, a stratified random sample procedure was used. The size of the sample for schools involved during the first year (the longitudinal study cohort) was $15 \%$. This sample was acceptable in respect of error and possible attrition of numbers. The sample size for schools involved during 2004 and 2005 (the annual groups) was also 15\% of Year 9 and 15\% of Year 10.

Descriptive statistical analysis was employed using graphical and numerical techniques for summarising data. These techniques included measures of central tendency, comparison of means using paired $t$-tests, measures of variability and analysis of variance. Particular attention was paid to the effects of the SSLI on boys and students in the lower quartile.

\section{Ecologically valid assessments}

By definition, standardised measures such as the ESA are not tailored to local, site-specific needs; in fact, part of their claim to 'objectivity' is that they are not. Additionally, unless they have a diagnostic dimension, they are not future orientated in the way a 'local' subject-specific unit pre-test can be (Barton, 2002). As such, they are insensitive to the local interventions of facilitators and teachers. The impact of local interventions is better measured by instrumentation that reflects what was taught for example; text structure, and how it was taught; for example, through the use of an effective literacy strategy. Local, teacher-made assessments that are tightly tailored to local curriculum are not alternatives to psychometric, norm-referenced measures (Gronlund \& Linn, 1990). Each form of these complementary assessments fulfils different purposes.

Seven participants teaching Years 9 and 10 English, health education, biology and physics in four of the SSLI 2003-2005 case study schools (see Whitehead, this issue) constructed ecologically valid teacher-made tests by re-design of their historic unit assessment measures to reflect students' academic literacy demands, and their use of literacy and thinking teaching tools. These measures privileged 'local' professional choice and reflected student needs. The results obtained from these assessments illustrated to teachers that by using appropriate literacy and thinking tools, and by constructing tests that reflected how they taught, they could make a difference to student outcomes. Their results indicated to researchers the uptake of literacy strategies, the efficacy of facilitators and the extent to which the school culture supported change. 


\section{Conclusion}

Given the complexity of what was being attempted in this research, the methodology needed to have both a within-school focus and a focus on the interaction between schools and outside professional development facilitation. The multiple approaches described here sought to tap data sources at different levels within schools through mixed methods, school-based, multi-sited case studies, regional school cluster focus groups, regional facilitators' focus groups, questionnaires and psychometric measures. Only with this complex, multidimensional methodological approach, we suggest, can the key issues attendant upon secondary literacy across the curriculum be effectively highlighted and analysed.

\section{Correspondence}

Any correspondence should be directed to Professor John Smyth, School of Education, University of Ballarat, Ballarat, Victoria 3353, Australia (j.smyth@ballarat.edu.au).

\section{References}

Alton-Lee, A. (2005) Collaborating across policy, research and practice: Knowledgebuilding for sustainable educational development. Paper presented at the OECD/Netherlands Evidence Based Policy Research Conference, The Hague, The Netherlands.

Alton-Lee, A., Rietveld, C., Klenner, L., Dalton, N., Diggins, C. and Town, S. (2000) Inclusive practice within the lived cultures of school communities: Research case studies in teaching, learning and inclusion. International Journal of Inclusive Education 4 (3), 179-210.

Amrein, A. and Berliner, D. (2002) High-stakes testing, uncertainty and student learning. Education Policy Analysis Archives 10 (8). http://epaa.edu/epaa/v10n18. Accessed 15.11.06.

Barton, D. (2002) Literacy practices in local activities: A case study of an ecological approach to literacy. In J.P. Hautecoeur (ed.) Ecological Education in Everyday Life (pp. 137-149). Toronto: University of Toronto Press.

Bell, D. (2003) Access and achievement in urban education: 10 years on. Speech to the Fabian Society, London, 20 November. http://www.ofsted.gov.uk/pressrelease/ index.cfm?fuseaction $=$ newsdetails\&id $=1506$.

Burgess, R. (1988) Conversations with a purpose: The ethnographic interview in educational research. Studies in Qualitative Methodology 1, 137-155.

Cohen, L., Manion, L. and Morrison, K. (2000) Research Methods in Education (2nd edn). London: Routledge \& Falmer.

Freebody, P., Ludwig, C. and Gunn, S. (1995) Everyday Literacy Practices In and Out of Schools in Low Socio-Economic Urban Communities (Vol. 1). Melbourne: Curriculum Corporation.

Freebody, P. and Wyatt-Smith, C. (2004) The assessment of literacy: Working the zone between 'system' and 'site' validity. Journal of Educational Enquiry 5 (2), 30-49.

Gronlund, N.E. and Linn, R.L. (1990) Measurement and Evaluation in Teaching (6th edn). New York: Macmillan.

Horkheimer, M. (1972) In M. Connell et al. (trans) Critical Theory: Selected Essays. New York: Herder \& Herder.

Ions, E. (1977) Against Behaviouralism: A Critique of Behavioural Science. Oxford: Blackwell. Marcus, G. (1998) Ethnography Through Thick and Thin. Princeton, NJ: Princeton University Press. 
Ministry of Education (2004) Effective Literacy Strategies in Years 9-13. Wellington, NZ: Learning Media.

New Zealand Council for Educational Research (NZCER) (2001) Essential Skills Assessment: Finding Information in Prose Text. Wellington, NZ: New Zealand Council for Educational Research.

Parlett, M. and Hamilton, D. (1975) Evaluation as illumination. In D. Tawney (ed.) Curriculum Evaluation Today: Trends and Implications (pp. 84-101). London: Macmillan.

Slee, R., Weiner, G. and Tomlinson, S. (eds) (1998) School Effectiveness for Whom? Challenges to the School Effectiveness and School Improvement Movements. London: Falmer.

Thrupp, M. and Lupton, R. (2006) Taking school contexts more seriously: The social justice challenge. British Journal of Educational Studies 54 (3), 308-328.

Whitehead, D., May, S. and Wright, N. (2004) Secondary Schools' Literacy Initiative (SSLI) Research Evaluation: Literacy Assessment and Achievement, 2003-2004. Hamilton, NZ: Wilf Malcolm Institute of Educational Research, University of Waikato.

Wilson, N. and McLean, S. (1994) Questionnaire Design: A Practical Introduction. Newtown Abbey: University of Ulster Press.

Wright, N., May, S., Smyth, J. and Whitehead, D. (2004) Secondary Schools Literacy Initiative Research Evaluation. Case Study Schools 2003. Hamilton, NZ: Wilf Malcolm Institute for Educational Research, University of Waikato.

Wright, N., May, S., Whitehead, D., Smyth, J. and Smyth, S. (2005) Secondary Schools' Literacy Initiative Research Evaluation. Sustaining Literacy Initiatives in Secondary Schools. Hamilton, NZ: Wilf Malcolm Institute for Educational Research, University of Waikato.

Wright, N., May, S., Whitehead, D., Smyth, J. and Smyth, S. (2006) Secondary Schools' Literacy Initiative Research Evaluation. Case Studies of Secondary Schools Literacy Clusters 2005. Hamilton, NZ: Wilf Malcolm Institute for Educational Research, University of Waikato.

Wright, N., Smyth, J., May, S. and Whitehead, D. (2003) Secondary Schools' Literacy Initiative (SSLI) Research Evaluation: Literacy Literature Review. Hamilton, NZ: Wilf Malcolm Institute of Educational Research, University of Waikato.

Wright, N., Smyth, J., May, S., Whitehead, D. and Smyth, S. (2005). Secondary Schools' Literacy Initiative Research Evaluation. Report on 2004 Case Study Schools. Hamilton, NZ: Wilf Malcolm Institute for Educational Research, University of Waikato. 